\title{
Clinical profile of poisoning in children presenting to pediatric intensive care unit
}

\author{
Sravan Kumar T ${ }^{1}$, Ramesh ${ }^{2}$, Usha Pranam ${ }^{3}$, Pranam G.M ${ }^{4}$, Manjunath G.A ${ }^{5}$ \\ ${ }^{1}$ Dr Sravan Kumar T, Junior Resident, ${ }^{2}$ Dr Ramesh, Associate Professor, ${ }^{3}$ Dr Usha Pranam, Assistant professor, \\ ${ }^{4}$ Dr Pranam G.M, Associate Professor, ${ }^{5}$ Dr. Manjunath G.A, Professor \& HOD, all authors are affiliated with \\ Department of Pediatrics, Navodaya Medical College, Mantralayam Road, Raichur, India.
}

Address for Correspondence: Dr Sravan Kumar T, Junior Resident, Department of Pediatrics, Navodaya Medical College, Mantralayam Road, Raichur. E-mail id: sravan.tsk.doc@gmail.com

\begin{abstract}
Introduction: Poisoning in pediatric age group became a challenging emergency in world that might be accidental, incidental or with snake bite or scorpion sting. In spite of many measures proposed by several organizations still the cases of poisoning are increasing. Methods: In this study above 1 month to 18 years of age children were included. Cases of food poisoning, allergic drug reactions were included along with scorpion sting and snake bite. Various parameter analyzed were age, sex, time of ingestion, type of poison, signs and symptoms, time taken to reach hospital, treatment offered, and complications underwent by the patient. Results: All the children who came with complaints of poisoning were admitted in the PICU. Total PICU admissions for 2 years were 693 out of which 27 cases were poisoning. Of total admissions $3.89 \%$ were poisoning cases. In total poisoning cases admitted female are 12 and males were 15. Accidentally ingested poisoning cases were 13, intentional ingested were 4 and poisoning due snake bite were 3 , scorpion sting were 7. In accidental ingested poisoning 1 is by Datura seeds. Poisoning by ingestion was of total 17 cases and other (scorpion sting and snake bite) are 10. On comparing with age 1-5 years children were more effected i.e, 15. Conclusion: It is retrospective study which showed accidental poisoning is commonly seen in under 5 age group children and incidental poisoning seen in above 10 age group children. In both groups parental counselling and safety measures improve the outcome. Early intervention of pediatric poisoning decreases morbidity and mortality in children.
\end{abstract}

Key words: Poisoning, Children, Pediatric age, Accidental ingestion

\section{Introduction}

Poisoning is a very common problem in pediatric age group in all developing and developed countries. There is almost $1-6 \%$ of bed occupancy of poisoning cases in India and out of that $3.9 \%$ getting admitted in PICU [1]. Poisoning in children commonly occur due to ingestion of non-consumable household products, drugs, pesticides, poisonous plant products by accidentally or intentionally. Products like kerosene, phenyl, bleaching powder, naphthalene balls, are common household products. Drugs like paracetamol, alprazolam, phenytoin, anti-thyroid drugs, anti-hypertensives, antidiabetic drugs. The other commonly seen poisoning cases are of sting bites, snake bites and animal bites. Plant poisons like Datura and mushroom.

Manuscript received: $14^{\text {th }}$ November 2016

Reviewed: $24^{\text {th }}$ November 2016

Author Corrected: $2^{\text {nd }}$ December 2016

Accepted for Publication: $9^{\text {th }}$ December 2016
According to the WHO and UNICEF poisoning in childhood is common because children are curious and explore their world their senses, most commonly by mouthing [2]. Toddlers are always at risk of accidental poisoning. Intentional poisoning is mostly seen in teenagers.

Now in children along with infectious diseases and malnutrition, accidental poisoning is becoming one of the important emergencies in the world. From most of the countries hospital statistics varying from $0.3 \%-7.6 \%$ of total number of cases admitted [3]. India reported more number of cases of both accidental and animal bite poisoning cases along with some of the other developing and developed countries. In most of the developed countries with early interventions and nearby good tertiary care centers, these emergencies are well 
managed. Inspite of several safety measures the world is still facing problem to reduce morbidity and mortality due to poisoning.

\section{Material and Methods}

This is a retrospective study conducted for a period of 2 years dated from August 2014 to August 2016 in 10 bedded PICUof Navodaya Medical College and Research Centre, Raichur. This study was approved by ethical committee of institution. It is one of the tertiary center available in Raichur district.
In this study above 1 month to 18 years of age children were included. Cases of food poisoning, allergic drug reactions were included along with scorpion sting and snake bite, other animal bite poisonings were excluded from the study. Variants analyzed were age, sex, time of ingestion, type of poison, signs and symptoms, time taken to reach hospital, treatment offered, and complications underwent by the patient. Relevant investigations were done depending on the poison ingested and for snake bite or scorpion sting.

\section{Results}

All the children who came with complaints of poisoning were admitted in the PICU. Total PICU admissions for 2 years were 693 out of which 27 cases were poisoning. Of total admissions 3.89\% were poisoning cases. In total poisoning cases admitted female are 12 and males were 15 . Accidentally ingested poisoning cases were 13 , intentional ingested were 4 and poisoning due snake bite were 3 , scorpion sting were 7 . In accidental ingested poisoning 1 is by Datura seeds. Poisoning by ingestion were of total 17 cases and other (scorpion sting and snake bite) are 10. On comparing with age 15 years children were more effected i.e, 15 .

Table No.-1: Showing number and percentage of cases effected with different poisonings.

\begin{tabular}{|c|c|c|c|}
\hline SL. NO & Type of Poisoning & No. of cases & Percentage \\
\hline 1. & Kerosene & 8 & 29.62 \\
\hline 2. & Scorpion bite & 7 & 25.92 \\
\hline 3. & Snake bite & 3 & 11.11 \\
\hline 4. & Paracetamol & 2 & 7.40 \\
\hline 5. & Alprazolam & 1 & 3.70 \\
\hline 6. & Phenytoin & 1 & 3.70 \\
\hline 7. & Spirit & 1 & 3.70 \\
\hline 8. & Lead & 1 & 3.70 \\
\hline 9. & Bleaching powder & 2 & 7.40 \\
\hline 10. & Phenyl & 1 & 3.70 \\
\hline 11. & Datura seeds & 1 & 3.70 \\
\hline
\end{tabular}

Our study showed that $81.48 \%$ patients had reached to hospital within 4 hours of poisoning and remaining patients came to hospital after 24 hours of poisoning with associated complications. Out of 8 kerosene 6 came within 4 hours of ingestion and remaining 2 came with pneumonitis after 24 hours. 1 case of scorpion sting which reached after 12 hours of poisoning went into complication of myocarditis. Remaining all the scorpion bite cases improved on giving prazosin and shifted out of PICU without any complications, 2 cases reached after 6 hours of poisoning. 3 cases of snake bite were treated with anti-snake venom and all the 3 cases reached in less than 2 hours of time from time of poisoning. Drugs like paracetamol, alprazolam, phenytoin were taken intentionally by teenagers because of psychological disturbances. They were stabilized and were given psychiatric counselling by the psychiatrist.

Different poisoning cases showed different symptoms. Kerosene poisoning showed breathless and cough. Snake bite and scorpion sting some cases showed lacrimation or frothing, some showed sweating, some showed breathless also. Accidental poisoning cases had vomiting's, pain abdomen. Each and every case had showed some different signs and symptoms. The following table shows common symptoms Table No.2 
Table No.-2: Showing different symptoms.

\begin{tabular}{|c|c|c|c|}
\hline SL. No & Symptoms & No. of cases & Percentage \\
\hline 1. & Vomiting & 12 & 44.4 \\
\hline 2. & Drowsiness & 6 & 22.2 \\
\hline 3. & Abdominal pain & 4 & 14.8 \\
\hline 4. & Frothing & 2 & 7.4 \\
\hline 5. & Unconsciousness & 1 & 3.7 \\
\hline 6. & Fever & 3 & 11.1 \\
\hline 7. & Loose stools & 2 & 7.4 \\
\hline 8. & Difficulty in breathing & 5 & 18.5 \\
\hline 9. & Sweating & 3 & 11.1 \\
\hline 10. & Lacrimation & 4 & 14.8 \\
\hline
\end{tabular}

\section{Discussion}

Poisoning in pediatric age group became most common emergency in India and all over the world. WHO and UNICEF had suggested so many safety measures, but still pediatric emergencies due to poisoning are still increasing day by day. This study was made on 27 patients admitted in PICU with Acute Poisoning. Each case with different poisoning was treated differently depending on the clinical presentation, history given by the attenders, poison ingested.

In our study most of the cases were accidental poisoning. Accidental poisoning is not only important in subject of toxicology but also important in field of pediatrics [4]. The incidence of accidental poisoning in pediatric age group was $1-7 \%$ [4,5]. In accidental poisoning kerosene is the most common hydrocarbon poisoning seen in India as it commonly used in villages for stoves and to lightening up wood for cooking. That was kept in approachable areas all the time. Toddlers who has nature of approaching and exploring things sometimes consumes it unknowingly to how it tastes. Kerosene has its toxicity which is directly related to its physical properties, specifically its viscosity, volatility, surface tension and chemical activity of side chains in their structure. Viscosity plays a major role for aspiration [6]. In our study accidental poisoning also includes bleaching powder, spirit, phenyl, Datura seeds, lead (wall paints). Bleaching powder is an hypochlorite solutionwhich on ingestion causes vomiting and corrosive injury to GIT and causes gastric irritation. But rarely causes strictures and serious injury such as perforation. Pulmonary complications may also be seen after ingestion. But our 2 cases of bleaching powder poisoning showed only esophageal irritation without any pulmonary complications. Spirit poisonings are less commonly seen in pediatric age group. Symptomatic approach should be the mainstay of treatment and gastric lavage can be done if patient reaches with in 1 hour of ingestion.

Datura and lead poisoning had CNS presentation with lot of irritability. On proper history and approach these can be diagnosed and can treated without having complications. 1-5yrs children were the patients admitted under accidental poisoning in our study.

In developing and developed countries incidental poisoning with pharmaceutical drugs is increasing due many psychological disturbances. Pharmaceutical compounds are the common agents of poisoning [9]. In our study all cases of drug poisoning are above 10 years of age. Paracetamol and anti-histamines are common drugs used for incidental poisoning [7,8]. In our study a 14 year old child who was on phenytoin for convulsions consumed 10-15 tablets at once because of suicidal tendency caused by disturbance in the family. Family is also plays a major role in incidental poisoning of children. Parents and children should be counselled by the psychiatrist. Children should grow in happy and healthy environment.

Snake bite and scorpion sting poisoning were also taken it as accidental poisoning. These poisonings are dangerous causing morbidity and mortality in children. Poisonous Snake bite more fatal than a scorpion sting. There are several 
factors contributing severity and outcome in snake bite [10] like size of the victim, part bitten, exercise, individual activity, number of bites, snake species, secondary infection, and treatment, (table no.3). In our study all 3 cases reached hospital within 4 hours. 2 cases were managed with ASV (anti-snake venom) and the other 1 out 3 is bite of a nonpoisonous snake.

Table No.-3: Showing factors contributing severity and outcome in snake bite.

\begin{tabular}{|c|c|c|}
\hline SL. No & Factors & Effect on outcome \\
\hline 1. & Size of victim & Bigger the size, the outcome will be good. Due less amount of toxin per $\mathrm{kg}$ \\
\hline 2. & Comorbidity & Predisposes to harmful effect of snake venom \\
\hline 3. & Part bitten & Bitten on trunk, face and directly into bloodstream have a worse prognosis \\
\hline 4. & Exercise & $\begin{array}{l}\text { Exertion following snakebite has poor outcome due to increased systemic } \\
\text { absorption. }\end{array}$ \\
\hline 5. & Individual sensitivity & Sensitivity of individual to venom modifies the clinical picture \\
\hline 6. & Bite characteristics & $\begin{array}{l}\text { Bite number, depth of bite, dry bite, bite through clothes, shoes, or other } \\
\text { protection; amount of venom injected, condition of fangs, and duration which } \\
\text { snake clings to the victim, all effect outcome. }\end{array}$ \\
\hline 7. & Snake species & Different species have different lethal dose, lethal period, and aggressiveness \\
\hline 8. & Secondary infection & Presence or absence of pathogenic organisms in the mouth of the snake \\
\hline 9. & Treatment & Nature of first aid given and time elapsed before first dose of anti-snake venom \\
\hline
\end{tabular}

Kerosene poisoning affects respiratory system most of the time and causes respiratory distress symptoms and less likely other systems get affected. Type II pneumocytes will be affected which results in decreased production of surfactant which in turn causes pneumatocele because of alveolar or airway wall rupture. Child has to be protected from respiratory complications [11]. In our study cases which were hospitalized late had pneumatocele. They were treated noninvasively, no child got requirement of mechanical ventilation.

Scorpion sting is common emergency in pediatric age group in and around the World. Most of the scorpion sting cases werehospitalized within 4 hours of sting. In our study all the sting cases did not present with acute symptoms. They were well managed with symptomatic treatment and shifted out of PICU after 24 hours of strict monitoring. Cases which presented with acute symptoms took at least of 48hours of PICU admission and all cases came out with prazosin, only 1 case went into complication of myocarditis as they got hospitalized after 24 hours of scorpion sting. My study infers accidental poisonings are more seen than other types of poisoning in pediatric age group.

\section{Conclusion}

It is retrospective study which showed accidental poisoning is commonly seen in under 5 age group children and incidental poisoning seen in above 10 age group children. In both groups parental counselling and safety measures improve the outcome. Early intervention of pediatric poisoning decreases morbidity and mortality in children.

Funding: Nil, Conflict of interest: None initiated, Perission from IRB: Yes

\section{References}

1. Aggarwal B, Rana SK, Chhavi N. Pattern of poisoning in children, an experience from a teaching hospital in northern India.JK Science.2014;16(4):174-8.
2. WHO-UNICEF. Children and poisoning: world report on child injury prevention. World Health Organization. 2008.

3. Buch NA, Ahmed K, Sethi AS. Poisoning in children. Indian Pediatr. 1991 May; 28(5):521-4.

4. Srivastava A, Peshin SS, Kaleekal T, Gupta SK. An epidemiological study of poisoning cases reported to the National Poisons Information Centre, All India Institute of Medical Sciences, New Delhi. Hum Exp Toxicol. 2005 Jun; 24(6):279-85.

5. Hyder AA, Wali S, Fishman S, Schenk E. The burden of unintentional injuries among the under-five 
population in South Asia. Acta Paediatr. 2008 Mar; 97 (3):267-75. doi: 10.1111/j.1651-2227.2008.00670.x.

6. Anderson CE, Loomis GA. Recognition and prevention of inhalant abuse. Am Fam Physician. 2003 Sep 1; 68 (5):869-74.

7. Pearn J, Nixon J, Ansford A, Corcoran A. Accidental poisoning in childhood: five year urban population study with 15 year analysis of fatality. Br Med J (Clin Res Ed). 1984 Jan 7; 288 (6410):44-6.

8. Basavaraj S, Pushpalatha K. Clinical profile and outcome of acute pediatric poisoning in urban tertiary care hospital. J Evid Based Med Healthc. 2015;2 (5): 459-63.
9. Sever M, Saz EU, Koşargelir M. An evaluation of the pediatric medico-legal admissions to a tertiary hospital emergency department. Ulus TravmaAcilCerrahiDerg. 2010 May;16(3):260-7.

10. Ahmed SM, Ahmed M, Nadeem A, Mahajan J, Choudhary A, Pal J. Emergency treatment of a snake bite: Pearls from literature. J Emerg Trauma Shock. 2008 Jul; 1(2):97-105. doi: 10.4103/0974-2700.43190.

11. Sunil Kumar M.N., Parvathy V.K. A Study of accidental ingestion of hydrocarbon in children in a medical college hospital in kerala: International journal of pediatric research 2016 May;5(3);295-301.

\section{How to cite this article?}

Sravan Kumar T, Ramesh, Usha Pranam, Pranam G.M, Manjunath G.A. Clinical profile of poisoning in children presenting to pediatric intensive care unit. J PediatrRes.2017;4(05):328-332.doi:10.17511/ijpr.2017.i05.07 